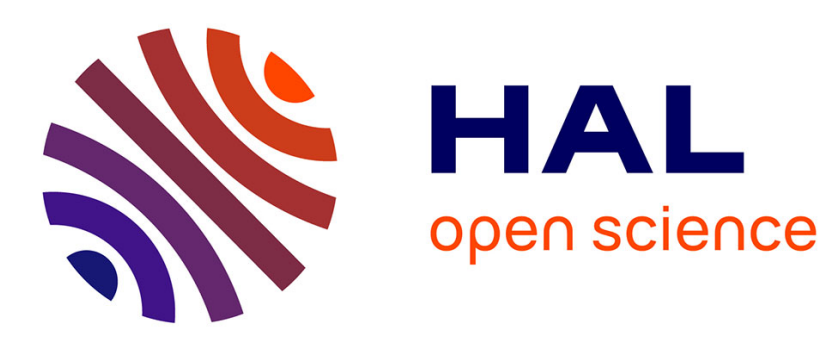

\title{
Effect of anthraquinone derivatives on canine and rat intestinal motility.
}

\author{
Rafael Garcia Villar, E Leng-Peschlow, Y Ruckebusch
}

\section{To cite this version:}

Rafael Garcia Villar, E Leng-Peschlow, Y Ruckebusch. Effect of anthraquinone derivatives on canine and rat intestinal motility.. Journal of Pharmacy and Pharmacology, 1980, 32 (5), pp.323-329. hal01562310

\section{HAL Id: hal-01562310 \\ https://hal.science/hal-01562310}

Submitted on 13 Jul 2017

HAL is a multi-disciplinary open access archive for the deposit and dissemination of scientific research documents, whether they are published or not. The documents may come from teaching and research institutions in France or abroad, or from public or private research centers.
L'archive ouverte pluridisciplinaire HAL, est destinée au dépôt et à la diffusion de documents scientifiques de niveau recherche, publiés ou non, émanant des établissements d'enseignement et de recherche français ou étrangers, des laboratoires publics ou privés.

\section{다(1)(2)}

Distributed under a Creative Commons Attribution - ShareAlikel 4.0 International 


\title{
Effect of anthraquinone derivatives on canine and $\because$ rat intestinal motility
}

\author{
R, GARCIA-VILLAR, ELKE LENG-PESCHLOW* AND X. RUCKEBUSCH
}

Laboratoire de Physiologie-Pharmacodynamie, Ecole Nationale Vétérinaire, 31076 Toulouse Cédex, France, *Pharmakologische Abteilung, Dr.'Madaus \& Co., Ostmerheimer Str. 198, D-5000 Köln 91, Germany

\begin{abstract}
The effects on gastrointestinal motility of 3 senna.preparations containing $18 \%$ oxidized Ca-sennosides, $60 \%$ Ca-sennosides, or pure sennosides $A+B$ were tested in dogs and rats as measured by electromyography. Oral administication of the oxidized products in the fasted animal increased the activity of the small intestine within $2 \mathrm{~h}$ and reduced both caecal and colonic contractions for $24 \mathrm{~h}$. Severe diarrhoed was present $4.6 \mathrm{~h}$ after administration and lasted for at least 1 day. Ca-senposides had a similar, but weaker effect while pure sennosides affected motility only $6-10 \mathrm{~h}$ after oral administration. The intracolonic administration of the oxidized products resulted in an immediate reduction of colon motility for $7-8 \mathrm{~h}$ and diarrhoea was present within $40 \mathrm{~min}$. Intracolonic Ca-sennosides and sennosides $\mathrm{A}+\mathrm{B}$ induced only small changes in the intestinal motility, but diarrhoea also appeared. The results confirm that pure sennosides act predominantly on large intestine motility after their degradation by colonic microorganisms. Qxidized products are already effective in the upper gastrointestinal tract. The early action of Ca-sennosides requires further investigation. Side effects after oral senna treationent such as griping or nausea may be caused by motility changes induced by the presence, of small amounts of oxidized products in the drug.
\end{abstract}

The consistency of facces is the result of the transit rate of the digesta and/or changes in intestinal absorption. The transit rate is normally closely related to variations in the myoelectrical activity of the gut, whereas changes in water and electrolyte. absorption are not necessarily caused by changes in motility. Continuous recordings of the electrical activity of the gut wall by chronically implanted electrodes allow an accurate assessment of motor phenomena in the conscious animal (Bueno et al 1975b, 1977; Code \& Marlett 1975; Ruckebusch 1970; Ruckebusch 1977; Ruckebusch \& Fioranionti 1975; Szurszewski 1969), Similar methods have already been used successfully to establish motility disturbances induced by castor oil, hyperosmotic mannitol, infections or sudden diet changes (Bueno et al 1975a; Christensen \& Freman 1972; Mathias et al 1976, 1977; Ruckebusch \& Buerio 1975; Stewart \& Bass 1976; Stewart et al 1975).

Senna glycosides (sennosides) which are respon: sible for the laxative action of senna, scem to pass the stomach and small intestine without being absorbed or attacked by gastric acid or intestinal enzymes. When they reach the large intestine they are broken down by micro-organisms into a pharmacologically active form that influences the motility of the colon as measured by visual observation or the balloon: technique (Breimer \& Baars 1976; Hardcastle \&

\footnotetext{
* Correspondence.
}

Wilkins 1970; Okada 1940; Schmid 1952; Schmidt 1960; Straub \& Triendl 1934; van Os 1976). As their effect on other parts of the gut has had less attention, although side effects that may originate from the upper gastrointestinal tract like griping or nausea are well-known (Glatzel 1972; Godding 1976; Richter 1966), we have examined three senna preparations for their effects on the whole gastrointestinal motility in conscious dogs and rats using the electromyographic method.

Animals : METHODS

Six mongrel dogs $(14-22 \mathrm{~kg})$ and $15 \mathrm{Wistar}$ rats $(300-350 \mathrm{~g})$ of either sex were housed individually in modified metabolism cages, the rats on a $12: 12$ light-6ark rhythm, and prepared with pairs of $\mathrm{Ni}-\mathrm{Cr}$ eketrodes (diameter $120 \mu \mathrm{m}$, length $100 \mathrm{~cm}$ in dogs; diameter $80 \mu \mathrm{m}$, length $50 \mathrm{~cm}$ in rats) chronically implanted into the gut wall (Bueno et al 1975b; Ruckebusch \& Fioramonti 1975).

10-12 pairs of electrodes were positioned at regular intervals from the antrum to the colon in dogs and 6-7 pairs in rats. The last electrode was placed on the distal colon in fogs and on the proximal colon ( $3 \mathrm{~cm}$ distal of the Valyula ileocaecalis) in rats. The free ends of the electrodes were brought subcutaneously to the back of the neck. One dog was fitted with a cannula (external diameter $15 \mathrm{~mm}$ ) in the proximal colon to allow intracolonic administra- 
tion of the drugs. Transit studies were performed in 180 fasted female Wistar rats (180-270 g), 5 per cage, on a 12:12 light-dark rhythm at $24 \pm 1{ }^{\circ} \mathrm{C}$.

\section{Electromyographic studies}

Recordings of the electrical activity were obtained from 1 to 4 weeks after surgery by connecting the free ends of the electrodes to an e.e.g. machine. Direct recording was at a paper speed of 0.7 or $1.2 \mathrm{~mm} \mathrm{~s}^{-1}$ and at a time constant of $0.1 \mathrm{~s}$. Spiking activity was also registered in an 'integrated' form after elimination of the slow waves by a high-pass filter, summed and plotted using a potentiometric recorder at a paper speed of $5 \mathrm{~cm} \mathrm{~h}^{-1}$ (Latour 1973). In dogs, records were visually evaluated. In rats, the number of migrating myoelectric complexes as well as the number of contraction periods per hour were counted for the antrum, the caecum and the colon. Statistical significance was assessed using the Student's $t$-test.

Test substances were given in hard gelatin capsules to dogs either $1 \mathrm{~h}$ before feeding or after fasting for $16 \mathrm{~h}$. Controls were on the same dog but without drug. Intracolonic administration of an aqueous suspension was also assessed in the dog with a colonic canula. Measurements from dogs were made continuously. In rats, single periods, each of $24-30 \mathrm{~h}$ were used. After the rats had fasted for $16 \mathrm{~h}$, a control measurement of $4-6 \mathrm{~h}$ was made, then the test substance as an aqueous suspension was administered by gastric tube and recordings made for 20-24 h. No experiment was repeated in the same animal before the normal motility pattern was reestablished and diarrhoea had disappeared.

\section{Drugs}

These were: Dried purified senna extract containing $60 \%$ Ca-sennosides $\mathrm{A}+\mathrm{B}$ according to the Bornträger reaction (Sandoz, Basel, Switzerland). Quality control* (h.p.l.c.) revealed a content of $48 \%$ sennosides $A+B, 2-3 \%$ rhein, the remainder being unidentified as no reference substances were available.

Dried purified senna extract containing $18 \% \mathrm{Ca}$ sennosides $\mathbf{A}+\mathbf{B}$ (Bombay Oil Company, India). This drug was completely oxidized* in an aqueous $\mathrm{FeCl}_{3}$-solution for $5 \mathrm{~h}$ at $130^{\circ} \mathrm{C}$. No intact $\mathrm{Ca}$ sennosides were present (t.l.c.), but rhein was found and there were some other spots which could not be identified because of the lack of reference substances.

* Performed by the chemical department of Madaus \& Co. (Cologne, G.F.R.).
Sennosides A + B (1:1, Roth, Karlsruhe, G.F.R.) mol. wt $862 \cdot 72$. Doses of test compounds were 20 $30 \mathrm{mg} \mathrm{kg}^{-1}$ orally and $10 \mathrm{mg} \mathrm{kg} \mathrm{k}^{-1}$ for intracolonic administration in the dog and $120 \mathrm{mg} \mathrm{kg}^{-1}$ in the rat. Doses and number of experiments are summarized in Table 1.

Table 1, Doses and number of experiments

\begin{tabular}{|c|c|c|c|c|}
\hline & $\begin{array}{c}\text { Fasted } \\
\text { dog } \\
\text { (oral) }\end{array}$ & $\begin{array}{c}\text { Fed } \\
\text { dog } \\
\text { (oral) }\end{array}$ & $\begin{array}{l}\text { Fasted } \\
\text { dog } \\
\text { (colonic) }\end{array}$ & $\begin{array}{c}\text { Fasted } \\
\text { rat } \\
\text { (oral) }\end{array}$ \\
\hline $\begin{array}{l}\text { Dose of drug } \\
\left(\mathrm{mg} \mathrm{kg}^{-1}\right)\end{array}$ & $20-30$ & $20-30$ & 10 & 120 \\
\hline & \multicolumn{4}{|c|}{ (No, of experiments) } \\
\hline $\begin{array}{l}\text { Senna extract } \\
60 \% A+B\end{array}$ & 8 & 4 & 2 & 10 \\
\hline $\begin{array}{l}\text { Senna extract } \\
18 \% \mathrm{~A}+\mathrm{B} \\
. \text { oxidized }\end{array}$ & 10 & 4 & 2 & 11 \\
\hline $\begin{array}{l}\text { Sennosides } \\
\mathrm{A}+\mathrm{B}\end{array}$ & 4 & & 2 & 4 \\
\hline
\end{tabular}

\section{Transit studies}

Drugs (Ca-sennosides or oxidized Ca-sennosides) were administered by gastric tube in doses of 90,120 or $250 \mathrm{mg} \mathrm{kg}^{-1}$ in $5 \mathrm{ml} \mathrm{1 \%}$ tragacanth solution at different times $(0,30,60,120$ or $240 \mathrm{~min})$ before administration of a coloured marker (carmine $1 \%$ dissolved in $1.5 \%$ tragacanth solution, $10 \mathrm{ml} \mathrm{kg}^{-1}$ oral), Controls received vehicle. Ten rats were used for each group. Carbachol chloride (Merck, Darmstadt; $4 \mathrm{ml}=1 \mathrm{mg} \mathrm{kg}^{-1}$ s.c.) was given at the same time as the carmine marker. This dose has been previously shown not to obscure significant effects of drugs on transit time, while inducing a regular flow of ingesta thus facilitating measurement of the coloured part of the intestine. 20 min later the animals were killed and the gastrointestinal tract was removed, gently stretched on filter paper and the length of the small intestine as well as the length of the coloured part measured and expressed as percent of the length of the whole small intestine.

\section{RESULTS}

\section{Dogs}

Controls showed migrating myoelectric complexes in the small intestine every $90-120 \mathrm{~min}$ from 10 to $24 \mathrm{~h}$ after the daily meal. These consisted of two phases, one of irregular spiking activity followed by a phase of regular spiking activity, in which all slow waves were superposed by action potentials (Fig. 1). At the same time, an increased electrical activity in the 


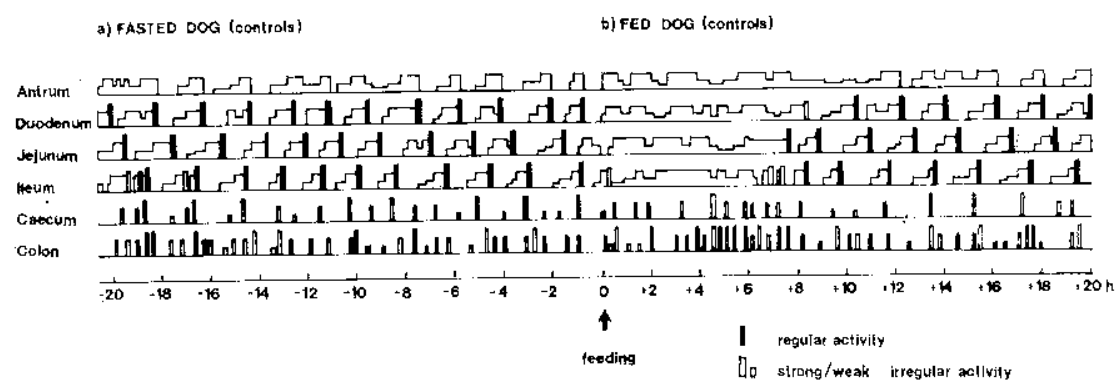

FrG. 1. Diagrammatic representation of the electrical activity in different parts of dog gastrointestinal tract before and after feeding.

antrum was recorded, whereas in both the caecum and colon contraction periods partly related to the arrival of a myoelectric complex in the ileum, occurred. After food, the motility of all parts of the intestine increased due to suppression of the quiescence periods.

After oral administration of Ca-sennosides to the fasted dog the myoelectric complexes in the small intestine disappeared for $13-20 \mathrm{~h}$. Caecal and colonic contraction frequencies were significantly depressed for about $24 \mathrm{~h}$ (Fig. 2) and severe diarrhoea occurred within 4-6h. Administration of the drug $1 \mathrm{~h}$ before feeding did not alter the normal postprandial pattern of the motility of the upper gastrointestinal tract (Fig. 2), but caecal and colonic motilities were depressed or, at least, the normal increase in colonic activity in response to feeding failed to appear. The diarrhoea was similar to that seen in the fasted dog.

The sennoside oxidation product by mouth also caused the myoelectric complexes of the jejunoileum in the fasted dog to disappear within $2 \mathrm{~h}$ for 12-14 h. Concomitantly, caecal and colonic motilities were significantly reduced for more than $24 \mathrm{~h}$ and diarrhoea occurred within $6 \mathrm{~h}$ for at least 1 day, whether the dog was fasted or fed (Fig. 3).

Pure sennosides did not affect the intestinal motility until $6 \mathrm{~h}$ after oral administration (Fig. 4). In 3 out of 4 experiments, antral and small intestinal motility were disorganized and the reduced contraction frequency in the caecum and colon $6-10 \mathrm{~h}$ after treatment became normal about $10 \mathrm{~h}$ later. There was a moderate laxative effect after $8-16 \mathrm{~h}$. In the 4 th experiment, there were no changes in motility and no diarrhoea. In contrast, the sennoside oxidation products placed in the colon immediately reduced its motility for $3-8 \mathrm{~h}$ and diarrhoea occurred $40 \mathrm{~min}$ later and lasted for some hours (Fig. 5). With the exception of the ileum, which tended to be disorganized with prolonged irregular actiivty and reduced regular activity, upper gastrointestinal motility was unaffected. Colon motility was mildly affected by intracolonic Ca-sennosides. Diarrhoea occurred some hours later and lasted for about 1 day. Pure sennosides by the same route produced severe diarrhoea within $30 \mathrm{~min}$, which lasted several days. There were no striking changes in the electrical activity. a) FASTED DOG

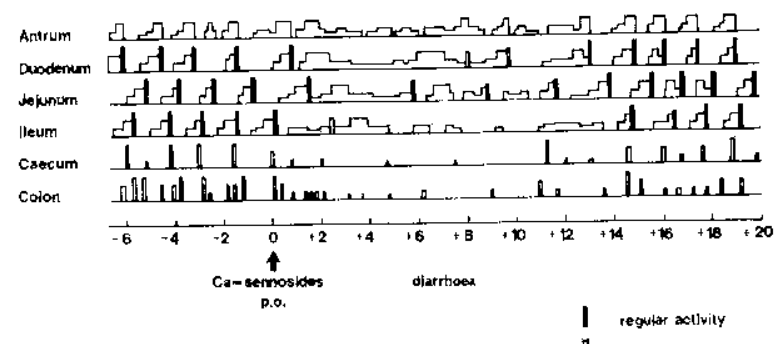

lo strong/weak inregular aclivity

FIG. 2. Motor effect of orally administered Ca-sennosides in a fasted (a) or fed dog (b). 
a) FASTED DOG

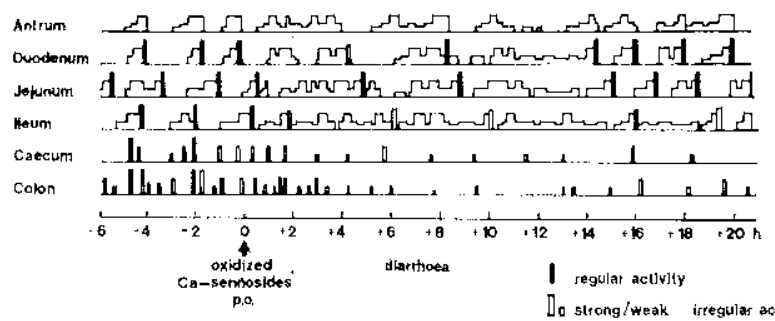

b) FED DOQ

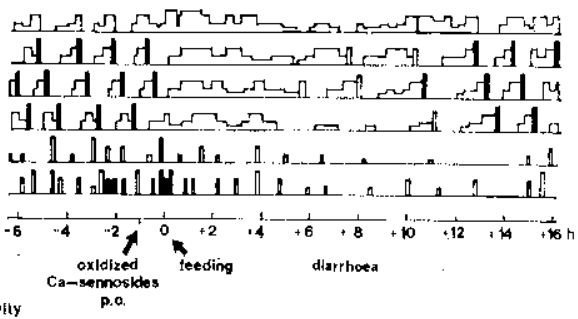

FIG. 3. Effect of orally administered oxidized sennosides in a fasted (a) or fed dog (b).
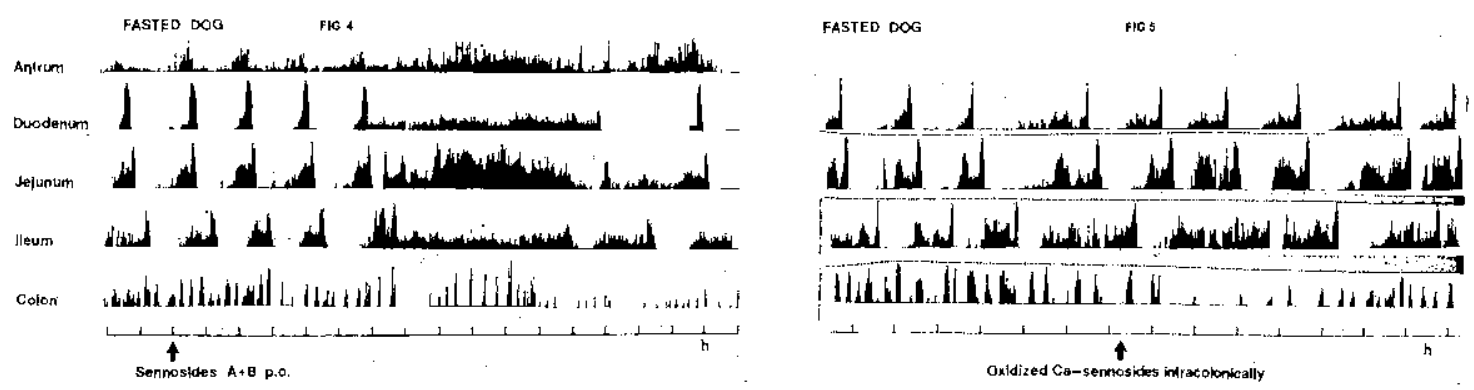

Fig. 4. Electrical activity summed at $20 \mathrm{~s}$ intervals of different parts of dog gastrointestinal tract after oral administration of pure sennosides.

Fig. 5. Electrical activity summed at $20 \mathrm{~s}$ intervals of different parts of dog gastrointestinal tract after colonic administration of oxidized Ca-sennosides.

\section{Rats}

Myoelectric complexes in the small intestine of untreated rats appeared every $15-25 \mathrm{~min}$ (see Ruckebusch \& Fioramonti 1975). The caecum showed short and distinct contraction periods interrupted by periods of quiescence. These contractions were continued in the colon and interspersed with periods of high level of spiking activity. As in the dog, continuous irregular spiking activity occurred after feeding. Oral administration of sennoside oxidation products and $\mathrm{Ca}$-sennosides resulted in a distinct diarrhoea in only $50 \%$ of the rats. Pure sennosides caused a laxative effect in only 1 out of 4 experiments.

Sennoside oxidation products significantly inhibited the number of myoelectric complexes in the duodenum, jejunum and ileum within $2 \mathrm{~h}$ and up to $20 \mathrm{~h}$ after administration (Fig. 6). Minimal values were reached progressively from duodenum to ileum. Antral activity remained unaffected, but caecal and colonic motility also dropped. Normal values were not obtained until after $20 \mathrm{~h}$. Casennosides had a similar, but milder effect on small intestinal motility, Colonic and caecal activities, however, were severely reduced with almost no sign of recovery after $20 \mathrm{~h}$. Pure sennosides showed no early effect on gastrointestinal motility in the 3 experiments in which no diarrhoea was evident. One experiment which resulted in a laxative effect, caused a slight reduction of the number of the myoelectric complexes in the small intestine and a pronounced depression of caeco-colonic motility.

The two senna extracts exerted no effect on small intestinal transit time. Neither different doses of the drugs nor different times of pretreatment resulted in significant changes in the coloured length of the small intestine compared with the control.

\section{DISCUSSION}

The normal intestinal myoelectrical activity found for dogs and rats corresponds with previous findings 
FASTED RAT . Antrum
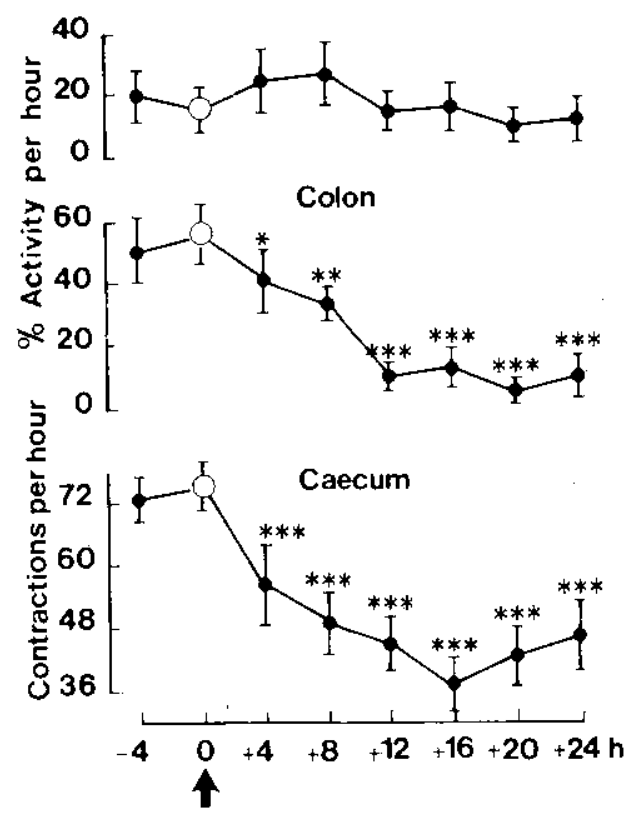

Ca-sennosides p.o.

FASTED RAT Antrum
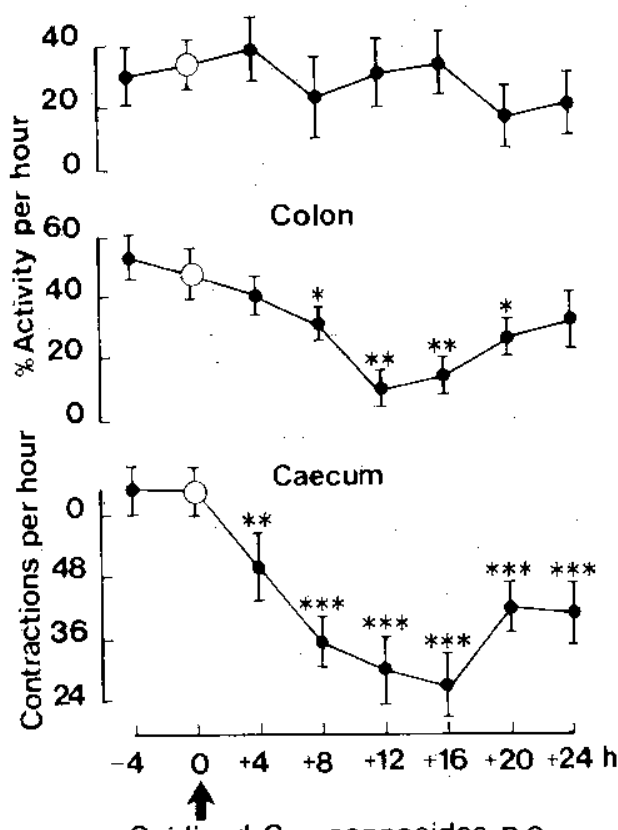

Oxidized Ca-sennosides p.o.
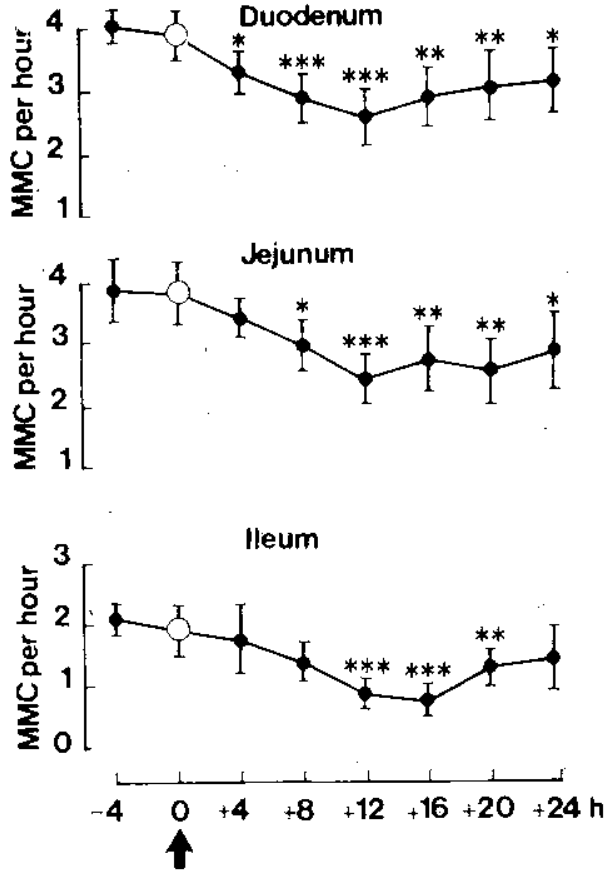

Ca-sennosides p.o.
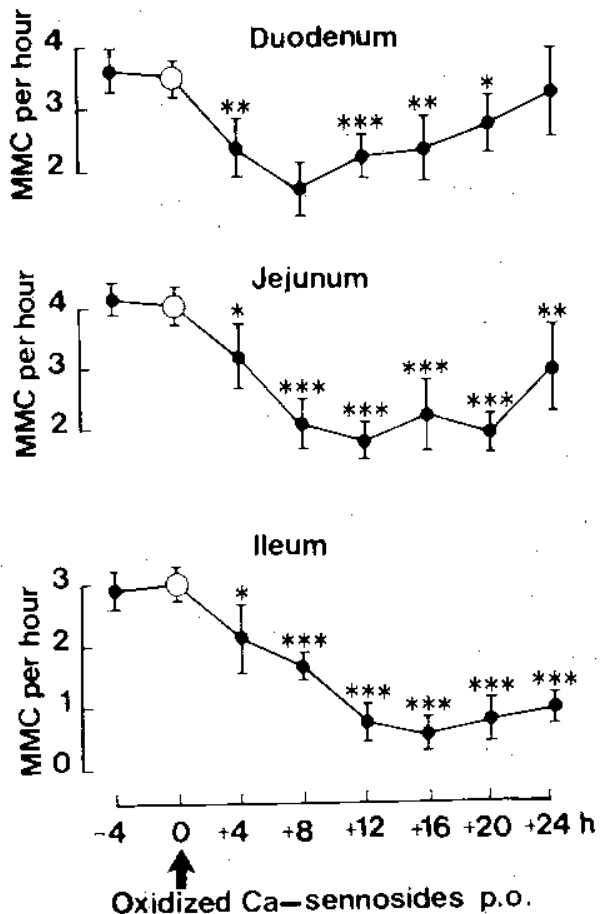

Oxidized Ca-sennosides p.o.

compared to 0

FIG. 6. Electrical activity in different parts of rat gastrointestinal tract after intragastric administration of Casennosides (top) or oxidized Ca-sennosides (bottom). 
(Bueno et al 1975b, 1977; Ruckebusch \& Fioramonti 1975).

Oral administration of Ca-sennosides or their oxidized products induced a sudden reduction or even a disappearance of the migrating myoelectric complexes, accompanied by a tendency towards a continuous irregular spiking activity in the small intestine and a pronounced reduction of colonic activity. Pure sennosides showed a $6-8 \mathrm{~h}$ delay before an effect was noticeable which may correspond to the transit time necessary to reach the large intestine. This supports the presumed mechanism of senna action in that sennosides have to be transformed by colonic microorganisms before becoming active. Their action on motility, however, was not restricted to the colon, the upper gastrointestinal tract was also affected, though to a lesser extent than with the other preparations. If the action of senna is based on a stimulation of the colonic myenteric neurons as was proposed by Okada (1940) and Smith (1968), the local effect may be spread by neural pathways and the degree of spread may be related to the concentration of active derivatives in the colon.

The sudden changes in motility of the small intestine after oral administration of oxidized $\mathrm{Ca}$ sennosides was not surprising as it is unreasonable to expect that they would specifically influence colon motor activity. The near simultancous reaction of the large intestine is evidence for reflex mechanisms which differ from those after eating in that colonic motility was not stimulated, but depressed. In rats, the gastrointestinal myoelcctric activity reacts very sensitively to oxidized Ca-sennosides, because motility disturbance were recorded even when no diarrhoea was apparent.

Surprisingly, Ca-sennosides administered orally had a similar effect on upper gastrointestinal motility as their oxidized products, in a time too short to allow their degradation in the large intestine. At present, the most likely explanation is that the action. on motility may be induced not by the Ca-sennosides themselves, but by contaminating compounds such as rhein and other Bornträger-positive substances (see Methods). This would mean that intestinal motility is a very sensitive indicator of the content of oxidized derivatives in senna drugs. An explanation in terms of the Ca-sennosides being less stable in acid $\mathrm{pH}$ of the stomach than non-salt sennosides seems unlikely. Intracolonic administration of oxidized $\mathrm{Ca}-$ sennosides induced an almost immediate effect on both colonic motility and stool production. Ileal motility was also affected. The effect of intracolonic
Ca-sennosides and sennosides $\mathbf{A}+\mathbf{B}$ on colonic motility was less pronounced, although diarrhoea occurred but the experiments with pure sennosides $\mathrm{A}+\mathrm{B}$ were not enough for definite conclusions to be drawn.

The relationship between changes in gastrointestinal motility and the induction of diarrhoea is not fully resolved. However, diarrhoea is normally accompanied by colonic hypomotility as is constipation by colonic hypermotility (Waller et al 1972; Wangel \& Deller 1965). This is explained by the loss of the normal segmenting contractions and therefore a smaller resistance to flow (Connell 1962). The reduced number of contractions in the colon after all three senna preparations indicates that a fast passage of the digesta through the colon may contribute to diarrhoeal conditions. In the rat, the flow rate in the small intestine was not increased. This was confirmed by preliminary experiments in the dog. Schmid (1952), using coloured food, also found that small intestinal transit time was hardly influenced by senna administered orally, but that time of passage along the colon was significantly reduced. In man, gastric emptying and small intestinal transit did not differ in constipation and diarrhoea, whereas time of passage along the colon was significantly faster in patients suffering from diarrhoea (Waller 1975). Oxidized senna placed via the colon stimulated the peristaltic response in a manner similar to other laxatives, e.g. bisacodyl and oxyphenisatin (Hardcastle \& Mann 1968; Hardcastle \& Wilkins 1970; Ritchie 1972).

The normal myoelectrical activity of the gut is often affected during diarrhoea (Stewart et al 1975; Stewart \& Bass 1976; Mathias et al 1977; Vantrappen et al 1977). The extent to which motility is influenced, seems to depend on the type of infection or on the drug used to induce diarrhoea. With senna, motility changes certainly play an important role in the laxative effect. Oxidized derivatives induce diarrhoea in a faster and more severe way than the sennosides themselves and may be responsible for undesired side effects.

\section{REFERENCES}

Breimer, D. D., Baars, A. J. (1976) Pharmacology 14 (Suppl, 1): $30-47$

Bueno, L., Dorchies, P., Ruckebusch, Y. (1975a) C.R. Soc. Biol. (Paris) 169: 1627-1632

Bueno, L., Fioramonti, J., Ruckebusch, Y. (1975b) J. Physiol. (London) 249: 69-85

Bueno, L., Garcia-Villar, R., Ruckebusch, Y. (1977) C.R. Acad, Sci. (Sér. D) (Paris) 285: 1463-1466 
Christensen, J., Freeman, B. W. (1972) Gastroenterology 63: 1011-1015

Code, C. F., Marlett, J. A. (1975) J. Physiol. (London) 246:289-309

Connell, A. M. (1962) Gut 3: 342-348

Glatzel, H. (1972) Z. Allg. Med. 48: 654-65.6

Godding, E. W. (1976) Pharmacology 14 (Suppl. 1): 78-101

Hardcastle, J. D., Mann, C. V. (1968) Gut 9: 512-520

Hardcastle, J. D., Wilkins, J. L. (1970) Ibid. 11: 10381042

Latour, A. (1973) Ann. Rech. Vet. 4: 347-353

Mathias, J. R., Carlson, G. M., DiMarino, A. J., Bertiger, G., Morton, H. E., Cohen, S. (1976) J. Clin. Invest. 58:91-96

Mathias, J. R., Carlson, G. M., Bertiger, G., Martin, J. L., Cohen, S. (1977) Am. J. Physiol. 232: E529E534

Okada, T. (1940) Tohoku J. Exp. Med. 38: 33-44

Richter, G. (1966) Dtsch. Apoth. Ztg. 106: 1829-1833

Ritchie, J. (1972) Gut 13: 211-219

Ruckebusch, M., Fioramonti, J. (1975) Gastroenterology 68: 1500-1508

Ruckebusch, Y. (1970) J. Physiol. (London) 210: 857882
Ruckebusch, Y. (1977) Zentralb1. Vet-Med. A24: 1-12

Ruckebusch, Y., Bueno, L. (1975) Am. J. Dig. Dis. 20: 1027-1034

Schmid, W. (1952) Arzneim. Forsch. 2: 6-20

Schmidt, H,-J. (1960) Mitt. Dtsch. Pharm. Ges. 30: 41-47

Smith, B. (1968) Gut 9: 139-143

Stewart, J. J., Bass, P. (1976) Gastroenterology 70: 371-376

Stewart, J. J., Gaginella, T. S., Olsen, W. A., Bass, P. (1975) J. Pharmacol. Exp. Ther. 192:458-467

Straub, W., Triendl, E. (1934) Naunyn-Schmiedebergs Arch. Exp. Pathol. Pharmakol. 175: 528-535

Szurszewski, J. H. (1969) Am. J. Physiol. 217: 17571763

van Os, F. H. L. (1976) Pharmacology 14 (Suppl, 1): 18-29

Vantrappen, G., Janssens, J., Hellemans, J., Ghoos, Y. (1977) J. Clin. Invest, 59: 1158-1166

Waller, S. L. (1975) Gut 16: 372-378

Waller, S, L., Misiewicz, J. J., Kiley; N. (1972) Gut 13: 805-811

Wangel, A. G., Deller; D. J. (1965) Gastroenterology $48 ; 69-84$ 
